\title{
Can our cities be planned? Does the function follow the form? The New York experience
}

\author{
Alberto Peñín Ibáñez ${ }^{1}$ Alberto Peñín Llobell ${ }^{2}$ \\ ${ }^{1}$ Escuela Técnica Superior de Arquitectura. Universitat Politècnica de València. Valencia, Spain \\ ${ }^{2}$ Universitat Politècnica de Catalunya, UPC, Barcelona, Spain \\ E-mail: apenin@penin.es, alberto.penin@upc.edu
}

\begin{abstract}
Do we need urban planning? For a better future, for a better territorial integration, for attending collective demands? New York is at the other side of the usual answer. Manhattan is an example of the versatility of a single pattern, drawn on a paper over a territory with very different features. When it comes to reality, it uniforms it, and fills it with progressive, unattended and renewed demands, with no more plan than the one that is demanded by an efficient economic system. Its urban plan (?) has just attended, quickly, private demands, giving flexibility to ground uses and GFAs, with no more worries than its functionality. As the only stable issue, as simple and clear as possible, has been the link between urban space and territory through a universal but fixed pattern. It allows free deals between developers and authority, respecting very few regulations, to enable changes, constructions, knocking offs and rehabilitations far from the European style urban plans. Which is its future in a democratic and free society? A government based constantly and with transparency on assemblies, not in a Plan, that can assure equal treatments and fair deals of the initiatives towards the community? Some of the proposals accepted in Manhattan, where the urban shape at its simplest stage of a horizontal pattern unchanged in its 200 years of existence, show us the success and failures of this system. Adapted from the beginning to a traded world, it has no bad urban nor social conscience. This frame matches perfectly the precapitalism of its founders with the demands of a contemporary globalized society.
\end{abstract}

Keywords: Manhattan, New York, Urban planning, Versatility,

Uniform pattern.

\section{Introduction}

This is in fact a rhetorical question and could be rephrased as follows: why and for what should we plan our cities?

The orthodox answer is placed on the administration, and has been increasingly broad: to attend to its future and plan its orderly urban development, to achieve a better territorial integration, and also to approach the collective needs of its population and, in a more social way, to answer the basic needs of those that do not have the means. A different, more recent answer, that comes from the strengthening of the market society and private initiatives, puts aside the administration, relegating it to a subsidiary role as a law guarantor.

If there are not goals and means at its disposal, that is to say, if there is no plan, what use are they in the cities? For a long time to have a Plan was a goal in itself, as an acknowledgment of good city government 2 . Reality gave us contradictory examples: there are many Plans without a plan, that respond to simple technical and administrative skills, or that are just presented to guarantee a plus value and real estate business in the city, one of the most lucrative activities in today's modern society. On the other extreme, the so called constituent Plans, are formulated gathering 
thousands of goals, some of them contradictory, with no order, priorities nor possibilities of carrying out their proposals, and so they have become another urbanistic fiasco.

Having an urban Plan in cities with a social democratic and free market system is somewhat about reaching a balance that is almost impossible to achieve between public goals and the intervention capacity of the Administration. How far should urban planning reach, and how should it be done? It certainly cannot be a deterministic Plan, with a final image of expected actions; it might be, in any case, an open Plan, with different alternatives and open scenarios, where governance, transparency and public participation would play a key role.

The best intervention made in a city -in our European culture- has consisted in having a Plan with very specific objectives concerning public utility and some general urban development lines, that may be up for modification in its small print, or in extreme cases, revised via some specific administrative steps. Thus, our best urban practise stands somewhere between a series of plans half utopian, half well-intentioned, that aimed to regulate land market and construction, and programmed relevant actions from the administration, and, on the other side, some very innocent plans in regards to the Market and its punctual real state demands, due to a lax regulation and a legal framework that allows for it to change. Meanwhile, social interest, better cities, and the quality of life of its inhabitants have escaped those goals.

Well, the Manhattan case, shows an heterodox answer of a Plan that consists of city plans and regulations that date back to the XIX century in a market society which content was -and is- to generate a urban grid where it is possible to, later, write the city speech freely, its future, with no regulatory constraints, where private investors chose -and choose- the place, rhythm and destiny of the land and the buildings and asked -and still askpublic representatives, the city government, to explicitly approve any action.

The big apple Plan was a support grid of multiple streets and blocks, homogenous from the formal point of view and with no limit in its extension, that covered the whole island from
North to South. It did not set any distinctions for pre-existing evidences -except for one old, small road- and its regulations allowed to urbanize them as needed, leaving facilities and services to the place and time when they were demanded and its installation was profitable. Any block could be dedicated to any kind of use or activity that their owners and developers decided, and if there were not appropriate, there were no problems to change or replace them. Here, function follows form, as a product of a pre capitalist society, with a very developed practical sense.

This orthodox urban planning pursued welfare, beauty and life quality, and design followed some theoretical demand expectations. The big fight to make this idealistic tale fit has provoked many thoughts and doctrinal adjustments. The main one is that we have gone from designing the future city to simply trying to survey, control and channel the strengths that drive its own development.

\section{The Manhattan case}

We will focus on Manhattan, one of the New York City's five district. Lewis Munford lucidly described its planning in a very graphical way: "the original city planners put in place some control systems to avoid its own scape, and maybe it will never scape". A design strategy, in the end, that refers to another text from Italo Calvino ("Invisible cities", 1972) where we are told that the reality of the city it contained within its boundaries like the lines of a hand, its scratches, its marks.

The Commissioners Plan was an orthogonal grid laid out in 1811 on top of the more than 5.880 Has of the Manhattan island (with average size of 21,6 by $2,8 \mathrm{~km}$ ), which has remained nearly unaltered for over 200 years, while the city grew exponentially and shaped modern New York, the metropolis par excellence.

In the years of its implementation, during its transformation from drawing to reality, there were few changes; among them the replacement of a large number of blocks by a huge open park, Central Park (1853), not planned by its planners. In the same manner, some spaces were open to leave room for large 
facilities such as Railway Stations, Columbia University or Lincoln Center.

Also during the process of its implantation and urbanization some small local squares were created, once proven its influence on the revaluation of the surrounding real estate. And after this, only minor adjustments were made, like the proposals for the renewal of Downtown, Midtown and other neighbourhoods, that were in some cases accompanied by Reform Plans. Because the grid pattern, once put in place (and once the logical initial problems with the owners were overcome) has proved strong in its essence and flexible in its implementation, especially in a place of the world as challenging, dynamic and very much provisional as New York.

There have been some important value judgements regarding the very idea of the grid, and old idea in fact, that has been widely used in the creation of new cities throughout history. For Le Corbusier, the Manhattan grid was, due to its uniformity and lack of structure, the biggest catastrophe for new urban planning in the beginning of the XXth century. Moreover, he was the one who proposed superblocks and hierarchized patterns; the density -he claimed- of the blocks and constructions at street level, prevented the city to have open spaces. His idea of a city of superblocks with towers surrounded by parks, was the opposite. Koolhaas ("Delirious New York"), on the other hand, offers the most well-known plan eulogy, both of its general principles and of the buildings that it generated.

The Plan was 'presented in 1807 by the Commissioners: Governor Morris, De Witty Rutherford, with engineer John Randel, as a "report" with plans and observations, and it was approved in 1811. It contained a huge pattern of 155 streets (E-W direction) and 12 avenues (S-N direction), perpendicular to the others. Which resulted in more than 2.323 blocks that covered the whole island, from the South harbour to river Harlem in the North, as a massive patchwork with no considerations to topography or pre-existing structures whatsoever. The blocks were horizontal rectangles of $60 \mathrm{~m}$ width between streets and 188 to $240 \mathrm{~m}$ width between avenues. The old New Amsterdam (the original Dutch harbour area, the Downtown) was reduced, to the South, to a different mesh, smaller and less rigid, around the old road to the harbour, Broadway Avenue. And a small exterior village, the Greenwich Village, was swallowed after establishing a short avenue with the same name, after which the historical core was left.

The Plan kept the trace of the "Broad way", a road to the outskirts on the North, reluctantly accepted as an "uncomfortable presence" or "erratic diagonal", as different authors called it. It crossed avenues in several points, up to 79th street where it merges with one of them. It remains as a diagonal, not exactly conceived to shorten distances -as it occurs in European extensions-, that, precisely due to its strange geometrical trace, has created integration conflicts at every cross and some important problems, but also at the same time, the most interesting renewal cases. Some of them are excellent urban examples: Union Square, 4th, Flatiron building Madison 5th, Herald 6th, Times square, 7th, Columbus Circus, 8th avenue.

The authors rejected the ongoing fashion of baroque lines, with star-shaped avenues and streets, because they presented execution problems and created inefficient blocks. Therefore, the shape was not selected lightly. On the contrary -they argued- "straight angles allow for straight house plans, easy to build and easy to use"; and that the rectangular blocks allowed, because of its shape and size, one "generalized cellular solution and an easy subdivision".

The Plan, simple and easy to understand, aimed to serve a rapidly growing demographic (from 120.000 to 1.200 .000 inhabitants in fifty years; today Manhattan island has 1.600.000), with a practically unlimited land offer and many kinds of possible plots, and was, in the end, a pattern that "if not the best, it was the one which less inconvenient had for its owners" where "housing and houses (have) straight sides and angles, the cheapest to build and the most convenient to live in" (Commissioners, 1811).

A proposal based in the principles of new capitalism: maximum offer, identic and general for everyone, and few and flexible urban conditions. If someone hoped for a justification 
related to the use, ways of life, personal relations or health standards, they would not find it. "Any consideration related to economy, intercommunication, financial future, health or aesthetics was left out of it" (J. Harder, 1898)

The urbanization process, as we advanced, brought some new issues in the grid: two avenues were added and different squares were created, before the introduction in 1853 , as we said, of Central Park, with 341 has, approximately $6 \%$ of all the urbanized area. Le Corbusier stated about it: "it is not a city conqueror but its prisoner"

Its urban consolidation was fast, mainly after the boost that entailed for Manhattan the creation of the new municipality of New York (1898), gathering the nearby districts -outside the island- of Bronx, Queens, Brooklyn and Staten Island. The island accommodated up to 2.000.000 inhabitants in the highest residential peaks; streets were open and hills dug out, in order to build, demolish and rebuild buildings and warehouses to make room for houses opening streets, dismantling hills, building, demolishing and rebuilding; warehouses were replaced by apartments and hotels, houses and churches by skyscrapers, in a process of "creative destruction" (Shumpeter) that characterize it.

The $30 \mathrm{~m}$ wide avenues and $20,50 \mathrm{~m}$ wide streets (the main ones being $30 \mathrm{~m}$ wide), had a simple correlative numbering that reinforce its isotropic and abstract character. Its sidewalks were at least $6 \mathrm{~m}$ wide (sometimes up to $23 \mathrm{~m}$ ) and 4.30 in the former and the latter, generous and useful sizes for any kind of use, and below them the technical services.

Traffic density and the high frequency of accidents, together with the high cost of an underground transport system, invited to the creation of elevated platforms for trains, especially for freight trains. Three large stations were built and, with an evident economic and technological effort, (the soil is granitic), an extensive subway network was finally open -in the early 20 's-, that eventually resulted in the gradual dismantlement of the high lanes. This network, the largest in the world, connected to the train and public bus networks, also extremely large and completed by an omnipresent taxi fleet of 13.000 , results in the fact that today -an unusual fact in the U.S.- more than $75 \%$ of its inhabitants do not have an own car.

Some adjustments were introduced that were directly caused by the road connections: first the bridges that stretched the grid in a specific direction; in 1848 to save Harlem River to the North, then in 1883 Brooklyn bridge to connect with the new neighbourhood at the other side of East River, and later Williamsburg Bridge (1903) and Manhattan Bridge (1909). The East Bridge was later connected by a tunnel (1904), followed by others. The renovation the of docks, the new tunnels and bridges towards the rest of the municipality and the State, a stimulated wager on the change of use in several areas and the recent creation of social housing complexes ("Projects") and parks on seafront of the city (on both sides of East and Hudson rivers) and the urban voids, have not and still do not challenge the validity of the urban mesh.

Finally, there has been logical adjustments to the road system and some removal of specific turns, in most cases motivated by the Broadway "wandering diagonal", a distressful subject, and origin of urban innovations in Manhattan. There have not been general reconversion proposals -except for some university projects as we will see-, nor any kind of new voids openings, traffic closing or pedestrian transformation, so common in Europe in the late XXth century. Not even in residential neighbourhoods.

\section{Some innovative proposals}

\section{Midtown}

Among the urban interventions carried out during those 200 years of the grid, that are interesting for our analysis of this heterodox approach, we must highlight the important change of use, building and image of the original pattern produced in Midtown and 42nd street. We could extend the citation to the Downtown, extremely shocked by the terrorist impact in 2011, but we do believe that the intermediate area of the city is a better and less conditioned example. 
In the 80's, Times Square area - the "Crossroad of the world" as it has been called-, with, again, Broadway Ave. crossing it, was a problematic area. Generally speaking, the Midtown was at the centre of attention during those years due to the pressure of new uses, with some depressed areas and other overcrowded.

After some preliminary reports, the Municipality Urban Department presented a Urban Development Plan, "Midtown Development Project", MDP (1981), a very complete document whose objective was to move the pressure from the East, full of offices and activities, to the West and South. It did not affect the famous grid, as it did the blocks and its building capacity conditions.

This Plan was a step further in the way urban interventions should be done in NY, creating a self- management organ, tax exemptions, a more free layout of the inside part of the blocks, and at the same time it simplified -it stated- the excessively extensive municipal regulations. It was something more than a report with use recommendations.

The Plan established:

* A delimitation of strategic differentiated areas of expansion, stabilization and conservation.

* Creation of an Economic Development Corporation of New York

* A bundle of tax and investment measures in West Side infrastructures

* A proposal of stabilization of the East Side to slow down its growth.

* An program of implementation of the Theatre District to preserve the theatres

* A FAR (Floor Area ratio), building capacity, different in the East and West areas

* Some investments in urban mechanical systems up to $\$ 817,4$ million, an unusual budget in Planning implementation.

* A simplification of the ordinance system, which was considered excessive.

The 1981 Plan finally benefited a voluntary internal change of the grid, with the creation of pedestrian networks crossing blocks or "arcades" and "squares" (with a minimum surface of $150 \mathrm{~m} 2$ and a $12 \mathrm{~m}$ side, and a front to the street proportioned to $3 / 1$ in relation to its depth), leaving to the developer an allowed construction coefficient gain 6 or 8 times the given ground; some interventions of urban acupuncture where its public character is underlined and that have been mostly successful.

\section{2nd Street}

It is the most well-known urban intervention in Manhattan where the application of the "Midtown Development Project" was carried out in a more evident manner.

Times Square, in the crossing of Broadway with 7th Ave., was in the XXth century the place for celebrations (end of the war and the successive New Year's eves) and leisure for New Yorkers and visitors. Its theatres and night lights made recognisable Broadway Avenue as the "Great White Way". In the 70's it had deteriorated in both its offer and image. MDP covered 5 Has around the crossing of said street, and has been considered in the city as a Plan model, because it counted on the support of the private sector, it had investments and financial incentives and it approached the transformation of the Midtown from the public sector.

In 1990, the Corporation in charge of urbanization received the authorization to close down any inconvenient activity. In two years, $2 / 3$ of them disappeared. During those 20 years, this action created many problems, but the private initiative for renovation never took off.

In 1993, the Administration in order to remake the Plan, hired Robert Stern, an architect with wide knowledge about NY and its historic architecture and who had worked for the Walt Disney Co. This way "42 Street Now!" was born, a plan for the urbanization of the 42nd street (report written in 1993). The Plan was called "Learning from 42nd Street", because of its relation with some of the principles of "Learning from Las Vegas", by Venturi and his collaborators.

With this idea, the 42nd street Plan intended, rather than to change its spatial features, to rebuild the popular perception of the street. His author stated: "On 42nd street, the lesson is to have fun. We are not making Disney, we are trying to bring a little sense of surprise, emotion, adventure". "It has been the most democratic 
of our fun places: theatres, restaurants and shops for entertainment and tourism, placing 42nd Street as a symbol of American culture and democracy".

Lastly, the Plan included a bet on small operations on public space that because of its unusual character are interesting, and as we understand, complementary to the 1981 Plan. Some street entrances, the always unpredictable Broadway Ave. crossing by, are closed to the traffic and provided with urban furniture, and fast food and drink kiosks. Those are successful actions as Times Square today is lively and full of people. Would it have been the case if the bet on public space had been stronger?

With those premises, it is not strange that Alexander J. Reichl, beyond the Times Square case, relates so firmly urbanism to politics and economy; the politic speech to economic interests and city policies to the political speeches. And where urban form, if it is compatible with those interests, becomes it support.

\section{Urban form consistency}

Adjustments in the pattern have been made in Manhattan, as we said. They have been mainly motivated by traffic density and transportation problems, congestion -when it has reached the limit- and because of the presence, both "uncomfortable" and hostile, of Broadway Avenue, the only exception to the initial grid made by the Commissioners Plan. It has increased the number of streets and squares, "pierced" and "repelled" its blocks, but in any case the physical implantation of the original grid has proven strong and very resistant to change. A sort of resilience that allows to come back to the original state after integrating change and exterior influences.

Thus, It is possible that the most durable and characteristic features of the city of New York are, at the same time, its condition as a permanent, open urban laboratory and its Cartesian grid of streets and avenues. Streets and avenues, not public spaces. It is a Plan, therefore, with goals and means... and management, heterodox, but which has resulted to be useful for its goals.
It should be mentioned, as a counterpoint, the Master Plan "PlaNYC, a greener, greater New York" (2007-2011), that brings us closer to proposals for regenerating the urban scene and conviviality, very different from the previous ones. Its incidence in the big questions regarding the future of the city (land, water, transportation, energy, air and clime change) and its bet for housing, for open spaces and abandoned plots, to "improve streets and sidewalks, adding new green streets and public spaces in every community", are questions that had not yet approached until then.

We have mentioned some other proposals related to the urban form that did not succeed. Specifically, the ones that were shown in an exhibition celebrated at the MOMA in 1967 integrating renewal designs for the residential neighbourhood of Northern Manhattan, made by the university team of Rowe and Schumacher at Cornell University.

Finally, it is worth mentioning the fact that the identification -or more accurately the recognition of the city- of inhabitants and visitors with its grid is evident. Even though it has very few spaces with high urban quality; this made Rowe himself to say that "where the grid remains neutral, its major 'qualities' can only be found in the most recognizable spaces (the continuous seafront, Central Park, Lower Manhattan, West Village, Broadway)".

Therefore, we are not discussing urban significance. NY constitutes the best proof than in any uniform grid, personal identification is mainly related to a conceptual or intellectual order; because the apparently endless network not only avoids selective and differentiated politics, but also human perception. We might wonder if in an urban metropole the size of NY there is room for the collective appreciation of its urban signs The recent exhibition in Valencia "Lost in the city" (2016-2017), is based on the individual vision of the places through their personal significance, rather than the existence of collective meaning.

Let us at least speak of the handicap that represents an isotropic, straight pattern that makes necessary a previous division of the city into smaller parts, in order to be able to apply selected urban politics, as the Midtown and 42 nd Street cases, previously mentioned. 


\section{If function follows form, is it necessary to plan?}

The case of New York, despite its importance, is an isolated case regarding the subject of the appropriation of the urban shape for different uses. Let us remember that new American colonization cities of the XVIth and XVIIth centuries had some strict regulations for the localisation of their inhabitants and for the segregation of public uses. However, their patterns were identical and their uses have changed with time. And in some other urban forms, predetermined and universal, such as the XIXth and XXth Spanish century urban extensions -the case of the Cerdà extension in Barcelona being the most emblematic-, some of the housing uses for the bourgeoisie are complemented by industrial and communal uses, using the same pattern of blocks and also have changed. This is still the case of Poble Nou, today 22@ district. And, we have to understand as well the current proposals of superblocks in both districts.

As a conclusion, the ability of the form, when it is simple and of enough dimension, to adapt to social uses, different and subsequent -not predetermined or even predictable- that a city requires throughout its evolution. The island of Manhattan, once flattened or filled (depending on the area), has been easy to divide in lots, and its urban form has been relatively indifferent to the uses that hereinafter are located. We must also highlight a certain resistance to change, once form is materialized, because of the cost that its re-urbanization would entail (not because of its buildings or of the compatibility with new uses of its lots) and the impact on ownership rights. New York is a paradigmatic case.

Then, an approach led by the administration, facing a liberal economic system of open market, with free circulation of people an in constant competition of its characters, today globalized; does it need to remain just an urban template?

Is this what planning is? It the answer is positive, we should face with no delay the doctrinal reformulation of our Plans. It would, undoubtedly reduce the tribulations, the elaborate doctrines and even our most thorough proposals. (Peñín, 2010)

\section{References}

BAERSON, A, director; SCHWARTZMAN A., KWARTER M., BARKAN A., and WHYTE W., "Midtown Development. A Report of the City Planning", City of New York City Planning, 1981,

BALLON, H, "The Greatest Grid, the Master Plan of Manhattan 1811-2011", Museum of the City of New York and Columbia University Press, 2012

BLOOMBERG, M. (OFFICE OF PLANNING AND SUSTAINABILITY, ADVISORY BOARD) AND COLABORATORS, "PLANNYC 2030, A Greener, Greeter New York", The City of New York, 2007

BRIDGES, W, 1811, "Remarks of the Commissioners for laying out streets and roads in the City of New York, under the Act of April, 3, 1807, compiled in "The greatest grid", 2012

BROWN L., DIXON D. y GILHAM O., "Urban design for an urban century. Placemaking for people", New Jersey, Wiley, 2009

CALDUCH CERVERA, JUAN, "La planificación de la ciudad como utopía", in "Textos dosificados. En torno a la arquitectura", Universidad de Alicante, 2010

GARCÍA CORTÉS, JOSE MIGUEL "Perdidos en la Ciudad. La vida urbana en las colecciones del IVAM", Exhibition catalogue, IVAM, 2016.

GRAMMENOS F. y LOVEGROVE G.R.,"Remaking the city street grid: a model for urban and suburban development", McFarland y Company, Nueva York, 2015

KOEPPEL, GERARD "City on a grid. How New York became New York", Da Capo Press, Philadelphia, 2015

KOOLHAS, REM "Delirious New York: A Retroactive Manifesto for Manhattan" Oxford University Press, New York, 1978

HERZOG, L.A. , "Return to the Center. Culture, space and city building in a global era", University of Texas Press, 2006

KOEPPEL, G, "City on a grid: How NY became NY", Da Capo Press, 1957 (new edition in 2016),

PEÑÍN, A. "Del Plan sin plan al Plan constituyente", Catalogue and exhibition of the 25th anniversary of the ETSA de 
Valencia, Urbanismo en la Comunidad

Valenciana 1965-90, UPV (1991)

PEÑÍN, A., "Urbanismo y crisis. Hacia un nuevo planeamiento general", Ediciones Generales de la Construcción, Valencia, 2006

REICHL, ALEXANDER J., "Reconstructing Times Square. Politics and Culture in Urban Development" University Press of Kansas, 1999

ROWE, C. y KOETTER F., "Collage City", Cambridge, Massachussetts Institute of Technology, MIT Press, 1978, published in Spanish by Gili in 1981

SAGALIN LYNNE B., "Times Square roulette : remaking the city icon", Cambridge, Massachusets Institute of Technology, MIT Press, 2001

STERN R.; FISHMAN D.; JACOB, T, "New York 2000: Architecture and Urbanism between Bicentennial and the Milenium", Monacelli Presss, New York, 2006

VENTURI R., SCOTT D. y IZANOUR S., "Learning from Las Vegas. The forgotten symbolism of architectural form" Massachusetts Institute Technology Press, Cambridge, 1977, published in Spanish by Gustavo Gili in 1998 